\title{
A Study To Assess The Effectiveness Of Self Instructional Module Among Staff Nurses Regarding Stress Management In Selected Hospitals Of The City
}

\author{
Sushma Manwatkar ${ }^{1}$ Susanne Mathew ${ }^{2}$ \\ ${ }^{I}$ (psychiatric nursing/Maharashtra University of Health Science, India) \\ ${ }_{2}^{2}$ (psychiatric nursing/Maharashtra University of Health Science, India)
}

\begin{abstract}
In today's world nurses are facing a lot of stress. Nursing practice involves many stressors related to both clients and the work environment. The present study was undertaken to assess the effectiveness of self instructional module regarding stress management among staff nurses in selected hospitals of the city using an evaluative approach. Objectives of the study were to assess the knowledge of stress management among staff nurses, to evaluate the effectiveness of self instructional module and to compare the level of knowledge on stress management with the selected demographic variables. One Group Pretest Posttest design was used to assess 60 samples selected by non probability convenient sampling technique. The pretest questionnaire was administrated and a SIM was distributed. The staff nurses were instructed to read the SIM and posttest was done of $7^{\text {th }}$ day of pretest. The data collected was analyzed using descriptive and inferential statistics. In data analysis it was found that the SIM was effective in improving the knowledge of staff nurses regarding stress management.
\end{abstract}

Keywords: effectiveness, stress among staff nurses, self instructional module, stress management, stress,

\section{Introduction}

Stress is an individual's physical, mental and emotional reaction to a condition that disturbs the normal equilibrium. Stress is any condition that harms the body and breaks down or causes death of few or many cells ${ }^{1}$. If Stress is intense, continuous or repeated, if the person is unable to cope or if support is lacking, then it becomes a negative phenomenon leading to physical illness and psychological disorders.

Stress has been regarded as an occupational hazard since the mid 1950, infact; occupation has been cited as a significant health problem. Work stress in nursing was first assessed in 1960 when Menzies identified four sources of anxiety among nurses; patient care, decision-making, taking responsibility and change. ${ }^{2}$ Nurses, like clients, are susceptible to experiencing anxiety and stress. Nursing practice involves many stressors related to both clients and the work environment-understaffing, increasing severity of client illnesses, adjusting to various work shifts, being expected to assume responsibilities for which one is not prepared, inadequate support from supervisors and peers, visiting homes that are depressing, caring for dying clients, and so on . The nurse's role has long been as stress-filled based upon the physical labor, human suffering work hours staffing and inter relationships that are central to the work nurses do since the mid 1980. However stress in nurses may be escalating due to the increasing use of technology, continuing rising care costs and turbulence within the work environment. Although most nurses cope effectively with the physical and emotional demands of nursing, in some situations nurses become overwhelmed and develop burnout ${ }^{3}$.

Bincy R conducted a pre-experimental study among 30 Critical Care Unit nurses working in Medical College Hospital in Kerala, India to assess the effect of stress management interventions such as Job Stress Awareness, Assertiveness Training, Time Management, and Progressive Muscle Relaxation on job stress. The results showed that caring for patients, general job requirements and workload were the major sources of stress for the nurses. The level of severe stress was reduced from 60 percent to 20 percent during post-test. The Stress Management Interventions were statistically effective in reducing the stress of nurses at $\mathrm{p}<0.001$ level. ${ }^{4}$

Nursing is a profession serving a vital role in health care team. There is an increase in hospital facilities and systems as the complexity of the patient care is intensifying. The size of the daily patient load has increased $\&$ client care has become more complex, but the size of nursing work force has not increased enough. Keeping nurses on this job proportionality and bridging new ones into the profession is a challenge. The job satisfactions and job career building opportunities are the important indicators, for the stability of the workforce. Improving the work environment is the key to retaining the existing nurses as well as attracting new recruits. Nurses need reasonable workload, supportive management, flexible work schedule, safe work place and opportunities to perform effectively ${ }^{5}$. 
Work life however, is not independent of family life; in fact these domains may even be in conflict. Stress may result from the combined respect of work, marriage and children. The effect of both work non-work stress among staff nurses have been studied infrequently. ${ }^{6}$

\section{Materials and Methods}

The study was based on a descriptive evaluatory approach. A single group pre-test and post-test design was chosen. The study was conducted in selected hospitals of Nagpur city in India. A sample of 60 staff nurses was chosen by using non-probability convenient sampling, working in selected hospitals of the city. The samples included were female staff nurses having an experience in the profession for a period above one year and who were willing to participate in study. The staff nurses who had undergone any training program on stress management and those who were going for long leave were excluded from the study.

The tools used in this study were a Self Instructional Module on Stress Management and a structured questionnaire to assess the effectiveness of the self instructional module. The tools were developed in two parts.

Part- I: This included the preparation and validation of Self Instructional Module by information collected from review of literature, discussion of the content with subject experts, and interaction with staff nurses to know their level of knowledge regarding the subject matter. The Self Instructional Module was prepared under the headings of - Definition and Concept, Causes, Signs and Symptoms and Stress Management Techniques. The final booklet was named as "Self Instructional Module on stress management".

Part II: This included the development of a structured questionnaire to assess the effectiveness of the self instructional module. It consisted of two sections.

Section A: It consisted of demographic profile of staff nurses. It had nine questions related to the age, marital status, religion, type of family, monthly family income, nursing qualification, designation, experience and area of working.

Section B: This section was a structured questionnaire having 30 items to assess the level of knowledge of staff nurses regarding stress management. The maximum score was 30 while minimum score was zero.

The investigators started data collection after taking informed consent from the study participants. The structured questionnaire was used to assess the knowledge of the staff nurses before administering the Self Instructional Module and five days after it.

\section{Result and Discussion}

The analysis of the data collected was done with the help of descriptive and inferential statistics. Demographic data of the samples showed that all of the samples $(100 \%)$ were diploma holders; majority of them were Hindus (86.7\%) and married (78.3\%); more than half of the samples were staff in-charges $(66.7 \%)$, had 11 or more years of experience $(65 \%)$ and belonged to nuclear families $(56.7 \%)$; and most of the samples $(48.3 \%)$ were from age group of above 35 years while minority of them had monthly family income of Rs. 5000-10000 $(30 \%)$ and were working in general ward $(36.7 \%)$.

While assessing the effectiveness of self instructional module on knowledge regarding stress management it was revealed that In pre test $36(60 \%)$ of staff nurses were having good knowledge, $35 \%$ having satisfactory knowledge, $3.33 \%$ had excellent level of knowledge and $1.67 \%$ had poor level of knowledge. The minimum score in pretest was 5 and the maximum score was 24 , the mean score for the pretest was 13.28 whereas in post test $44(73.33 \%$ ) of staff nurses were having very good knowledge, $16.67 \%$ having good knowledge, $8.33 \%$ had excellent level of knowledge and only $1.67 \%$ were having satisfactory level of knowledge. The minimum score in post test was 10 and the maximum score was 27 , the mean score for the post test was 20.86 .

\section{Bar graph showing significance of difference between knowledge score in pre and post test of staff nurses} in relation to knowledge regarding stress management

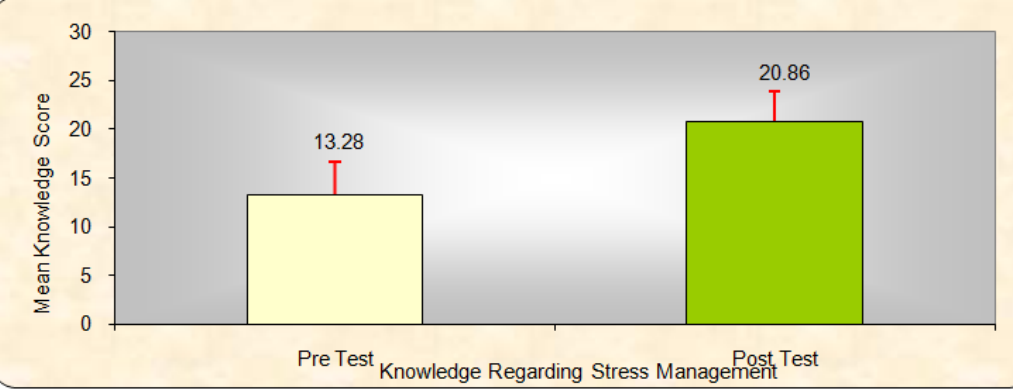


The following study conducted in France also showed results similar to the current study. Poncet MC, Toullic P, Papazian L, Kentish B N, Timsit JF, Pochard F et.al., conducted a survey on Burnout Syndrome (BOS) to identify determinants of BOS in critical care nursing staff working in 278 ICUs in France using Maslach Burnout Inventory data . Of the 2,392 respondents $82 \%$ were females, $80 \%$ were nurses, $15 \%$ were nursing assistants and 5\% were head nurses. Severe BOS-related symptoms were identified in $790(33 \%)$ respondents. By multivariate analysis, four domains were associated with severe BOS: (1) personal characteristics such as age (2) organizational factors such as ability to choose days off; (3) quality of working relations such as conflicts with patients, relationship with head nurse or physicians and (4) end-of-life related factors, such as caring for a dying patient, and number of decisions to forego life-sustaining treatments in the last week. The study concluded that one-third of ICU nursing staff had severe BOS. Areas for improvement identified in the study include conflict prevention, participation in ICU research groups, and better management of end-of-life care. The researchers recommend interventional studies to investigate these potentially preventive strategies. $^{7}$

\section{Recommendation}

Keeping in mind the results of the current study the researchers recommend conducting following studies:

- A similar study can be replicated with a control group and on a larger sample.

- A study can be conducted to assess the effectiveness of Self Instructional Module on stress management techniques for all health professionals working in different areas of healthcare.

- An experimental study can be conducted to assess the effectiveness of various stress management techniques among staff nurses.

\section{Conclusion}

The pretest result showed that the staff nurses did not have 100\% knowledge regarding stress management. The ' $t$ ' test computed to find out association between mean post test knowledge score and mean pre test knowledge score indicates significant gain in knowledge in all areas. Thus, it was concluded that self instructional module was effective. There was statistically no significant association found between knowledge score and demographic variables. The result of the study clearly showed that the Self Instructional Module had a positive effect on the knowledge of staff nurses. After the study majority of the staff nurses had opinioned that they liked the Self Instructional Module and that it was very informative.

Similar studies can help the nurses for promoting theirs' as well as the client's mental health . All hospitals should feel responsible for the well-being of their workforce as it proportionately improves safety standards of their patients. Nurses' positive attitude to their work markedly increases patient satisfaction and patient loyalty. Nurses as health professionals have an obligation to study the level of stress and coping strategies in different areas of nursing, in order to maximize the benefit of these strategies and to enjoy a successful and meaningful career. Therefore the investigators were interested to explore more aspects regarding stress and coping among staff nurses. It can be suggested that there is a need for increased awareness of the emotional demands faced by today's nursing workforce as well as the need for more experienced nurses to serve as mentors to those just entering the nursing profession.

\section{Acknowledgement}

First of all, we praise and thank lord almighty for his abundant grace and blessings throughout the study. We would like to give thanks to all the study subjects who have given their valuable time and honest responses to the questions which were put forward to them for this research study. We express our heartfelt gratitude to the teachers of VSPMs CON for their valuable suggestion from the initiation of this project till its conclusion. The researchers would also like to thank family, friends, colleagues, well wishers and all others who directly or indirectly supported and guided us during the study.

\section{Reference}

[1]. S.K. Avasthi, A comparative study to assess occupational stress level among male female employees of selected hospital at Indore, M.Sc. Nursing Dissertation, Devi Ahilya Vishwavidyalay, Indore, 2007.

[2]. B. Mishra, SC Mehta Evaluation of work place stress in health university workers, Indian journal of community medicine, 36(1), 2011.

[3]. A Berman, G Erb, B Kozier, SJ Snyder, Fundamentals of nursing concepts process and practice (Dorling Kindersley, India:2009)

[4]. Light Irin C and Bincy R, Effect of stress management interventions on job stress among nurses working in critical care units, Nursing Journal of India. 103(6), 2012, 269-71.

[5]. Uma R. Adhikari, A study to identified specific problem faced by the married staff nurses between the age of 25-45years in rendering nursing services in a selected private hospital in Kolkata, Nursing Image. 11(5).

[6]. Bonnie M. Jennings, Work stress and burnout among nurses: role of the work environment and working conditions, patient safety quality, handbook of nurses (Rockville: Agency for health care research and; 2008)

[7]. Poncet MC, Toullic P, Papazian L, Kentish-Barnes N, Timsit JF, Pochard F . Burnout syndrome in critical care nursing staff. American journal of respiratory and critical care medicine. 175(7), 2007,698-704. 